Editorial

\title{
News and Participation through and beyond Proprietary Platforms in an Age of Social Media
}

\author{
Oscar Westlund ${ }^{1,2,3, *}$ and Mats Ekström ${ }^{3}$ \\ ${ }^{1}$ Department of Journalism and Media Studies, Oslo Metropolitan University, 0130 Oslo, Norway; \\ E-Mail: oscar.westlund@oslomet.no \\ 2 Department for Journalism, Volda University College, 6103 Volda, Norway \\ ${ }^{3}$ Department of Journalism, Media and Communication, University of Gothenburg, 40530 Gothenburg, Sweden; \\ E-Mail: mats.ekstrom@jmg.gu.se \\ * Corresponding author
}

Submitted: 8 October 2018 | Published: 8 November 2018

\begin{abstract}
The link between journalism and participation has since long been envisioned and argued to be an important one. However, it is also a complex link. It encompasses how the news media and their social actors actively work towards enabling and engaging citizens as active participants through the digital infrastructures of their proprietary platforms, as well as the ways citizens potentially make use of such opportunities or not in their everyday lives, and how this affects epistemologies of news journalism. However, to date, journalism studies scholars have mostly focused on positive forms of participatory journalism via proprietary platforms, and thus fail to account for and problematize dark participation and participation taking place on social media platforms non-proprietary to the news media. This introduction, and the thematic issue as a whole, attempts to address this void. The introduction discusses three key aspects of journalism's relationship with participation: 1) proprietary or non-proprietary platforms, 2) participants, and 3) positive or dark participation.
\end{abstract}

\section{Keywords}

digital intermediaries; epistemology; participatory journalism; social media

\section{Issue}

This editorial is part of the issue "News and Participation through and beyond Proprietary Platforms in an Age of Social Media", edited by Oscar Westlund (Oslo Metropolitan University, Norway) and Mats Ekström (University of Gothenburg, Sweden).

(C) 2018 by the authors; licensee Cogitatio (Lisbon, Portugal). This article is licensed under a Creative Commons Attribution 4.0 International License (CC BY).

\section{Introduction}

Let us begin by borrowing the concept of 'taken for grantedness', as sociologically developed in a book focusing on how clocks, cars and mobile phones over time have become taken for granted aspects of everyday life and society (Ling, 2012). Mobile devices are indeed essential to the everyday life for most citizens; for communication, for information, for entertainment, and also for the functioning of society more generally. People rely on their mobile devices, and as long as they function as intended and as long as others are accessible via them, we tend to take them for granted. Mobile devices have become like air to humans and water to the fish; fundamental to everyday life and yet something we are rarely cognizant of being there. The act in which a person takes something for granted has both its advantages and disadvantages. As humans we clearly need to take certain things for granted in our everyday lives, and develop routine behaviors to avoid spending extensive cognitive effort in assessing information and making decisions. Feeling that we are able to take something for granted thus comes with certain advantages, such as when by depending on our smartphones providing us with the means to communicate, we get informed and entertained (alongside a plethora of additional contributions) literally at almost any time and at any place. Disadvantages become especially salient when sudden or organic changes cause 
disruptions. For example, when there is a societal crisis causing telecom networks or the power grid to go down, we quickly become aware of exactly how much we depend on our mobile devices. Such 'taken for grantedness' extends beyond the private realm to how diverse organizations rely on technologies such as mobile devices. It also applies to much wider phenomena, including but not limited to people taking for granted that professionally produced and published 'journalism' will continue to be available. Similarly, it might be the case that people assume citizen's participatory practices, via news sites, mobile applications, social media platforms etc. will be marked as largely positive as opposed to 'dark participation' such as when people spread misinformation, engage in media manipulation or online harassment (see Quandt, 2018). Dark participation differs from 'dark social media', such as Facebook groups and messaging apps that are not open to the public (Swart, Peters, \& Broersma, 2018). Moreover, people may also take for granted that social media platform companies will manage private data carefully, whilst providing a range of services 'for free'. The mere act in which a person takes something for granted essentially means this person makes an assumption about how things are or how things work. Such an assumption, as a statement we assume is either true or false, leads us to conclude things are in a certain way. It is disadvantageous if people in general, and scholars and journalists more specifically, hold on to such assumptions which perhaps rather should be brought into scrutiny.

This thematic issue has emerged based on a perceived need to question and re-assess our assumptions about the so-called participatory journalism. Scholars have typically focused on positive forms of participatory journalism via proprietary platforms, and thus fail to account for and problematize dark participation and participation taking place on social media platforms nonproprietary to the news media. Research into participatory journalism has often departed from an assumption that it will be closely linked to civic engagement and democracy. It has focused on the ways in which news media and journalists enable (as opposed to disable) active forms of participation in the news through proprietary digital platforms (especially the news site). For example, Robinson and Wang (2018) convincingly conclude that the civic act of participation in the news has not done much to democratize the flows of information in society, and also that those in control of platforms have much power in relation to network infrastructures and maintaining specific interests. Robinson and Wang (2018) do well in pointing out that such power certainly varies in different transnational contexts. Thus, while platform companies such as Facebook and Google have exceptional power and influence on some markets, the governments in certain countries (such as China) have enforced regulation that diminishes such power. This can also take place in the European Union (EU). For example, September 12th might become remembered as the day when the EU killed the free internet as we know it, voting in favor of the "Copyright Directive" that would mean enforcing rules that prevent sharing of non-copyrighted materials, etc.

Social media platforms have largely taken over as the sites where active participation with the news takes place. Welcomed or not by the news media, these platforms also involve direct exchanges between journalists/editors and citizens. The news media are actively customizing and publishing news for non-proprietary platforms, via for example branded Facebook groups and Twitter accounts (see, e.g., Cornia, Sehl, Levy, \& Nielsen, 2018), while at the same time struggling with not becoming too dependent on these platforms. Journalists themselves also use diverse platforms to brand themselves, conveying both personal and professional information, as well as relatable and reliable information (Holton \& Molyneux, 2018). Journalists who have many 'followers' on social media platforms like twitter are likely to attract audiences for their news material, and may also, as Kligler-Vilenchik and Tenenboim (in press) shows, enroll them into the news production processes.

This thematic issue also addresses the role of platforms, that there are many participants in diverse forms of contemporary journalism, and that the subsequent outcomes of participation are not necessarily positive but also take shape as 'dark participation'. In this editorial we turn now to discuss the core concept 'journalism'. This provides an essential point of departure for the subsequent discussion of how journalism intersects with participation across proprietary and non-proprietary platforms. We then turn to three key aspects of journalism's relationship with participation: 1) proprietary or non-proprietary platforms, 2) participants, and 3) positive or dark participation. Throughout the article we discuss key findings and contributions from the articles in the thematic issue, by way of relevance to these key aspects (as opposed to the running order conventionally used in an editorial).

\section{Journalism: A News Production Process}

Institutions of journalism are often seen as one if not the most important knowledge-producing institution in society, because they continuously scrutinize and report on what is happening in society, and thus make it possible for citizens to be informed. Scholars, practitioners, pundits and the public in Western democracies have largely taken for granted that journalism is and will remain being a key feature of democratic countries in the future. Many scholars in journalism studies and political communication have been working under the assumption that journalism functions as a 'Fourth Estate' successfully scrutinizing politics and power (e.g., Peters \& Broersma, 2016), and also that the news produced by the so-called professional journalists plays a crucial role in informing the citizenry, so they can participate in democratic processes in society. Many scholars have debated that one should 
not uncritically assume journalism is a fourth estate in society just because it normatively claims it should be and wants to be. There is a wealth of research taken for granted as support of journalism and the news media having had great significance in society (i.e., decades of research in highly regarded communication journals). For example, various studies witness how citizens who frequently access political news are also more interested and informed about politics and more likely to engage in specific kinds of democratic processes, such as voting. With much of this research building narrowly on surveys and panels, therefore closely linked to problems in survey responses and normative assumptions in such responses, it would be fruitful to assess passive trace data on what news people actually turn to, how long they spend with it, and link this to different kinds of activities related to democracy. A recent special issue in Digital Journalism focused on measurable journalism, i.e., how analytics and metrics are being integrated into news work, and how this enables future research to address inquiries in news ways, including the impact different kinds of journalism really has for participation in democratic processes (Carlson, 2018; cf. Powers, 2018). Measurable journalism means news media companies are increasingly equipped to monitor and analyze the diverse ways people consume and actively engage with the news via sharing, commenting, etc. (Costera Meijer \& Groot Kormelink, 2015), and through their behaviors - whether consumers accept or reject the epistemic knowledgethe journalists' claims made in the news can now be measured in more diverse and sophisticated ways (Ekström \& Westlund, in press).

Whatever the role is that we may ascribe to journalism in society up until now, the situation for journalism appears to be worsening, and thus our expectations of it definitely are in need of modification. We should not take for granted that all legacy news media in the future will have the resources to maintain well-staffed newsrooms and highly skilled and knowledgeable journalists who are granted time and resources to carry out high quality journalism. The business model of legacy news media such as newspapers has shown to have a diminished performance. This has been attributed to changing patterns in news consumption, transforming advertising models and expenditures while also stiffening competition from platform companies such as Facebook and Google (Nielsen, 2016), which offer their platforms for nearly anyone to produce, publish and access news and other content. Moreover, in many instances these are now functioning as digital intermediaries between producers and audiences of the news.

The 21st century has indeed been marked by debates, studies and speculations about the future of journalism. Interestingly, not only is the 'future' of journalism uncertain and bringing forth diverging viewpoints, but also the very idea of what 'journalism' is. In response, boundaries of journalism which have been contested have been maintained by journalists and institutions of journalism in diverse ways (Carlson \& Lewis, 2015), and the journalists seek to maintain journalistic authority in many ways, including through a meta-journalistic discourse (Carlson, 2016, 2017). When it comes to defining news journalism it has been commonplace to define it as closely interlinked to institutional news organizations (i.e., legacy news media such as newspapers, television and radio broadcasters) and industry associations (e.g., World Association of Newspapers) that accommodate 'professional journalists'. Basically, such a definition of 'what journalism is' concerns what journalists in these specific institutional arrangements do. Importantly, scholars have called for the broadening of our understanding of journalism, arguing that one should go beyond the individual journalist and institutional news media organization (Deuze \& Witschge, 2018). Thus, the traditional definition essentially helps conserve the legitimacy of these institutions, but beyond that it helps little in defining what journalism really is. This definition is narrow in defining who does journalism. In the past, journalists in relatively few news media organizations produced and published news material in a medium they owned and controlled (i.e., proprietary platform), and in several cases the reach was very high and thus translated into being a mass medium (e.g., Lewis, 2012). Nowadays there are a plethora of actors producing 'news', some of whom shift between human and computational ways of producing, some of whom attempt to be neutral, and others who try to make personal gains. These actors may also publish their 'news' for proprietary and non-proprietary platforms, and call to mind the diverse ways we may now think of 'news'.

In our view, 'journalism' does not simply translate into something being done by journalists, nor is 'news' equal to the outcome of journalism. News can be seen as a public knowledge claiming to report on current events in the world, but with many different genres, there are many different kinds of events covered in news. As a 'product' that is published, news can take many different forms and can be the result of different news production processes. Consequently, we make a call for conceiving of journalism on the basis of the ways in which the news, as a form of knowledge, is being produced. We argue that news journalism is based on what diverse social actors or technological actants do in the processes of making news (cf. Lewis \& Westlund, 2015).

In extension of this argument, our basic definition of journalism reads as follows: news journalism concerns performing a news production process with ambitions towards the publishing of truthful accounts of current events in the world. This definition does not presuppose that journalism can only be accomplished by those working for institutional news media (or having formal journalism education), but rather it is open to considering anyone being able to perform acts of journalism (including automated journalism). This of course does not mean that everyone has the competence, resources and time to produce and publish news, nor the platforms to reach 
a wider audience (and this definition does not limit itself only to proprietary platforms). In extension of the above, things clearly become more complex; can we take for granted that everyone who is a journalist or works for a news publisher indeed engages in a journalistic news production process? How are we to perceive materials that look just like news from diverse actors, including but not limited to 'alternative media (see Holt, 2018) and independent news producers, who produce 'news', 'information' as well as 'misinformation'? Moreover, and as shown by Ferrer and Karlsson (2018), also native advertising is produced to look similar to news.

First of all, research must delve into epistemologies of journalism. Throughout the world we find journalists who clearly subscribe to ideals and norms of being neutral watchdogs that report 'facts' about important events taking place. Importantly, journalists do not simply gather and report 'facts' as news, but engage in a process of producing the news. News production is, in this line, a form of knowledge production, and in the case of journalism, epistemology-the study of knowledge-is the study of how those producing the news not only know what they know, but also know of the evaluation, articulation and justification of their knowledge claims. News take shape as different forms of knowledge, depending on genres, length, etc. (see., e.g., review in Ekström \& Westlund, in press). Most importantly, let us proceed by contending that news journalism has been associated with authoritative and verified public knowledge about current events (Carlson, 2017; Ekström, 2002), but also that there are different epistemologies of journalism, with differences between TV, print and online journalism (Ekström \& Westlund, in press). In extension of this, we also find different epistemologies of digital journalism. Structured journalism, for example, puts its emphasis on completeness and accuracy, compared to giving priority to immediacy as is the case with much online journalism, and especially so when it comes to live blogging (e.g., Thorsen \& Jackson, 2018).

\section{Participation across Proprietary and Non-Proprietary Platforms}

Having discussed 'journalism', let us now turn to how it intersects with diverse forms of public participation. There are several epistemologies of journalism, and thus we should ask what the epistemologies of participatory journalism are, and also what is participatory journalism to start with? Participatory journalism has been defined and approached as a form of journalism where a specific actor, such as legacy news media (or other established institutions of journalism), open up their organization, their news work and their proprietary platforms to the public for them participate in. More generally, Anderson and Reevers (2018) discuss that the epistemology of news participation concerns how journalistic knowledge emerges on the basis of both pro- fessional expertise and public interaction (i.e., participation). A key contribution of theirs involves turning to the key epistemological question of how journalists know what they know, then moving forward with the idea that their knowledge could improve if they were to get involved with a participatory public. Their largely retrospective article brings forth an analysis of four important moments in the ongoing transformations of participatory epistemology, from Indymedia to diverse initiatives aimed at professional adaptations to participatory journalism, on a path towards what the authors refer to as quasi-participatory platforms (like Facebook). The fourth and final moment is described as a sort of participatory apocalypse by Anderson and Reevers (2018). It is embodied by the example of Pepe the Frog, the meme cartoon character that became a key symbol for the altright movement (cf. Holt, 2018, on alternative media).

It has often been held that in the public there are billions of eyes, viewpoints and competencies and that all, and increasingly easily, can feed into journalism and thus help enrich it (Borger, van Hoof, Costera Meijer, \& Sanders, 2013). Based on this understanding of what participatory journalism is, early and influential crossnational research concluded that participation for most part was confined to the very first stage of the news production process, with the public providing journalists with tips, pictures and videos, and the final stage when news materials were published and the audience commented on the articles (Singer et al., 2011). Research reviews have made apparent the great tensions between professional journalists desire and need for control, as opposed to open participation. By ceding control over some aspects of news production and circulation, journalists thus open up their traditional gatekeeping purview over what's classified as news (Lewis, 2012). Throughout the 2000s many news publishers experimented with, and developed, functions for participatory journalism. These primarily involved users providing journalists with source material, such as photos and videos, as well as possibilities for adding their interpretation through comment functions. Very few allowed citizens to participate in other stages of the news production process, and many news publishers have ceased to offer comment functions, as difficulties in maintaining a good tone overwhelmed their provision. Numerous news media companies have struggled with members of the public engaging in hate speech, bullying, racism and other forms of the so-called dark participation (see Quandt, 2018). Others keep on working towards fostering public participation, but are more strategic in the ways they involve the audiences. A German study of Spiegel Online, the biggest news media forum in the country, employed automated content analysis to examine a total of 673,361 user comments. The analysis included all incoming comments, finding that a prominent moderation strategy involved deleting user comments (more than one third of all comments were deleted). The rationale for deleting user comments was closely connected to of- 
fenses being made in relation to 20 politically sensitive topics, while offenses on other topics (even swear words) were still published (Boberg, Schatto-Eckrodt, Frischlich, \& Quandt, 2018). Longitudinal research has found that audience participation, including commenting on articles on news sites, initially rose for several years but then fell back down (Karlsson, Bergström, Clerwall, \& Fast, 2015). It is potentially dangerous to assume such developments mean that the audiences are in fact disinterested in participating in journalism, as the actions of audiences should also be analyzed in relation to how social actors are in fact enabling or restricting the affordances for participation offered by news sites and other proprietary platforms (i.e., the technological actants). The social actors can tailor their proprietary technological actants to enable as little or as much participation as they would like, and thus are in charge of setting the scene. This should be taken into account whether news publishers implement affordances for participatory journalism or not, and whether the digital design of their platforms carry incentives for the public to participate or not (cf. Novak, 2018). Robinson and Wang (2018) write, "the very definition of 'participation' morphs according to the locality and its political and information infrastructure; each place has its own structuring system with varying formal/informal relationships as well as different restrictions and allowances for participation in mediated spaces" (p. 92). Other scholars have argued there should be a sort of reciprocity in the relationship between journalists and their audiences (Lewis, Holton, \& Coddington, 2014), then it cannot come as a surprise that empiric studies find relatively 'limited' participation.

As part of the impetus for this thematic issue we argue that a key problem here is that journalism scholars treat 'participatory journalism' too narrowly, essentially in terms of their news sites. Over the past decade there has been tremendous research on participation activities, starting with blogs and accelerating with social media, allowing people to act as produsers, switching back and forth between being producers and users (Bruns, 2012). Lewis and Molyneux (2018) review and critically discuss a massive body of research focusing on the intersection of journalism and social media over the past decade. They intentionally seek to provoke and question participation in their article, which unpacks three problematic yet very influential assumptions in research about social media in journalism studies. They challenge assumptions: 1 ) that social media is a net positive; 2 ) that social media reflects reality; and 3 ) that social media matters over and above other factors. They conclude "these assumptions, even while implicit, may be clouding our collective judgment and obscuring issues that otherwise call out for our attention" (p. 19). Among the areas potentially where our judgement is clouded, we find the power of platform companies.

Importantly, research into social media in journalism has largely been disconnected from the core research positioning itself as focusing on participatory journalism.
While there may be many reasons for this, it seems plausible to us that until recently journalism studies scholars have largely perceived participation in journalism and news through social media as something distinctive from participatory journalism. If so, we encourage scholars to consider changing their perceptions. By bringing in social media into our understanding of what participatory journalism is, we can significantly change some of the conclusions we have made, including that the public is disinterested in engaging in discussions about news (cf. Swart, Broersma, \& Peters, 2018).

To date, scholars in the field of journalism studies have done little to distinguish between the proprietary platforms of the news media and the platforms which are non-proprietary to them (e.g., social media). Yet the news media, journalists and other news producers, actively and frequently turn to social media platforms to publish and distribute their news content, and/or enable the public to share and discuss their news material. A news publisher may well have decided to restrict any form of participatory functionalities on their proprietary site, for various reasons, while they on the other hand have created and maintain official and branded pages and channels for non-proprietary platforms such as Facebook, Twitter, Instagram, Youtube, Snapchat and Telegram. In all of these cases the institutions of journalism are running and supporting somewhat controlled environments for participation, albeit in non-proprietary platforms, and in different ways depending on what Robinson and Wang (2018) call transnational context. Should institutionally supported enabling of participation in platforms nonproprietary to the news media count as 'participatory journalism'? We would say 'yes', and certainly think this makes sense since social media platforms have developed and put on offer platforms with affordances for news publishing and news participation.

Indeed, we have seen institutions of journalism that have both encouraged and set restrictions on how their journalists approach and act on social media in terms of participation. Belair-Gagnon's in-depth study of developments at the BBC, for example, showed how there were increasing expectations on their journalists to create and actively use social media in their work (BelairGagnon, 2015). There is a wealth of research on how journalists use Twitter. For example, how journalists engage with the public or are extracting information from the public. A study focused on how one journalist, Andy Carvin at the NPR, used Twitter in diverse ways during the Arab Spring. For example, he frequently turned to his base of Twitter followers (around 50,000 at the time) to get their help in comprehending different kinds of information (Hermida, Lewis, \& Zamith, 2014). All in all, quantitative content analysis showed that non-elite actors were used as sources more often than elite sources, as opposed to what otherwise is common (cf. van Leuven, Kruikemeier, Lecheler, \& Hermans, 2018). A recent multimethod study from Israel documents how an individual journalist established a WhatsApp community through 
which she engaged a diverse set of citizens as participants and co-constructors of journalism in literally all stages of the news production process (Kligler-Vilenchik $\&$ Tenenboim, in press). These studies differ in terms of time periods, countries, and social media platforms. The common denominator, however, is that individual journalists use non-proprietary platforms that enable the public to participate in the news production processes. This leads us to the next theme, namely the participants.

\section{Participants in Journalism}

Let us return to the question of who performs journalism, and who participates in such news work. Once upon a time journalists would more or less run the entire show at the newspaper or broadcaster, from deciding which beats to follow and make news stories about, to which to publish. In the past, newspapers were typically organized as silos, separating the editorial department from the market/business department, but many have re-configured. With several news publishers now having developed and maintained digital journalism for 25 years, not only have their portfolio of publishing platforms expanded and their business changed, they have also had to acquire different technical and human resources, as well as re-organized themselves. In short, ten years ago news publishers started involving technologists in both daily routines and practices, and in innovation projects ranging from the development of blogs (Nielsen, 2012) to mobile news services (Westlund, 2011). Making a call for a more holistic approach, Lewis and Westlund (2015) have encouraged journalism scholars to not only study the perceptions and actions of the journalistic actors, but also technologists and businesspeople, and in relation to technological actants and audiences. Why? Well, because many news publishers are hiring or involving more and more technologists in their news work (such as digital developers, UX designers, data scientists, database developers, etc.), and are also working towards more collaboration between journalists and businesspeople. For example, a study of data journalists and civil technologists shows four different ways in which these work with data together, and create new entanglements (Baack, 2018). In building on recent scholarship on interloper media and the journalistic field (Eldridge, 2018), Holton and Belair-Gagnon's (2018) article identifies and makes distinctions between a set of three key 'strangers' (i.e., social actors) that bring diverse expertise into their participation in news production, acting as either disruptors or innovators. First, explicit interlopers are the "nontraditional journalism actors who may not necessarily be welcomed or defined as journalists and work on the periphery of the profession while directly contributing content or products to the creation and distribution of news" (p. 73). Second, implicit interlopers have less clear associations with journalism per se, yet make important contributions to it, and thus can be more easily welcomed. Third, media intralopers are defined as working for news media organizations, "bringing non-traditional journalistic expertise and perspectives to news organizations and disrupting news production through advancements in digital and social technology" (p. 73).

Building on this, one may ask if involvement by diverse 'strangers' and 'social actors' such as technologists, inside or beyond the news producing institution, should be conceived of as a form of 'participatory journalism'? Our answer is: it depends. In the case of involving civil technologists, who are working with technology that may enable civic participation (Baack, 2018), the answer is 'yes', because they constitute a form of public with special expertise. When it comes to journalists involving technologists in news production the defining criterion to consider concerns whether they collaborate on something intended to facilitate one or several forms of participation on behalf of the public. These discussions of participatory journalism are closely related to 'citizen journalism', as well as 'alternative media'. These categories include heterogeneous forms of news and information production and are marked by being carried out by others than traditional institutions of journalism (those typically referred to as legacy news media). In our perception of what counts as journalism, and the boundary work that surrounds those doing it, one often finds simplistic demarcation lines between those performing journalism, and others. Importantly, those "others" comprises a heterogeneous group of actors. For the salient case of 'alternative media', Holt's (2018) article discusses how these oftentimes are lumped together and perceived, collectively, as similar to one another, whilst their orientations, intentions, epistemologies and so forth may in fact diverge substantially. In an attempt to forward the heterogeneous characters of alternative media, Holt posits a $2 \times 2$ matrix that builds on the notion of anti-systemness, distinguishing between ideological anti-systemness and relational anti-systemness. While 'alternative media' often are successful in enrolling certain groups of citizens in participation, this does not mean they represent a form of participatory journalism by default. Alternative media clearly produce and publish one-sided stories and perspectives, whereas others are trying to adhere to common principles and routines for news production.

\section{Positive and Dark Sides of Participation}

As discussed at the outset, many are the scholars (and also practitioners, pundits and policy makers) who have worked under the assumption that the enabling of participation in news will have positive effects for civic engagement and democracy. Normatively it would of course be great if citizens were to engage themselves in diverse democratic processes, being enthusiastic about sharing their expertise and investing their time in assisting the news media in producing news, by checking facts, sending diverse materials and so forth. Clearly, by now we can make a list of instances around the world where this has happened, and especially situations where there 
has been some sort of benefit for the citizens in doing so (such as financial reimbursement or personal recognition). However, the once optimistic visions for the future of participatory journalism have not materialized in the ways once envisaged (see, e.g., Borger et al., 2013; Singer et al., 2011). The reasons for this are found not only in looking at the interest in doing so among the audiences, but also in taking into consideration the perceptions and actions of social actors such as journalists, and the enabling and disabling features of the technological actants as such.

This thematic issue comprises studies focusing on both positive and dark forms of participation, looking both backwards and onwards. Ruotsalainen and Villli (2018) present us with a discourse study of how 41 entrepreneurial journalism outlets have presented themselves (in their 'About Us' pages), focusing on participatory tendencies and their journalistic ethos. They find ideals closely connected to identity, niche, network and change, but also linked to 'traditional journalism' (cf. Witschge \& Harbers, 2018). Altogether Ruotsalainen and Villi (2018) conclude that there is a form of 'hybrid engagement', essentially translating into the difficulties of simultaneously adhering to traditional values and criteria of journalism on the one hand, and maintaining a participation and dialogue friendly approach on the other. Ruotsalainen and Villi (2018) proceed by sketching out four different possible scenarios for entrepreneurial journalism for the future, some which entail a dialogue with the public, and others which put little emphasis on such elements. While Ruotsalainen and Villi (2018) approach participation as a mostly positive phenomenon that news media industries may choose to work with or not, other articles in the thematic issue have critically examined the more heterogeneous nature of participation, and especially, the darker sides of it.

Anderson and Reevers (2018) chart an analysis of how participatory journalism has emerged and developed over time, including unexpected developments affecting cultural values as well as epistemologies. They discuss how public interaction has brought change to journalistic knowledge and professional expertise. This is something which they here refer to as participatory epistemology, and which they analyze by means of four key moments, which taken together point to how the concept of participation has transformed from being largely utopian to becoming more dystopian. Their article goes in harmony with the 'Dark Participation' article by Quandt (2018), which reviews and critically confronts much previous literature into journalism and participation. Quandt presents us with a rhetorically strong review, taking us on a critically marked journey into the positive and dark ends of participation. With a personal address, Quandt discusses how numerous scholars (including himself) approached citizen participation with naively positive mindsets and theoretical concepts beginning in the 1990s. He discusses how academics and others largely idealized human condition as well as social re- ality, writing that "media managers' economic fantasies of a willing, free workforce were equally misguided as the rather naïve academic notions of a revitalized journalism in direct debate with its active users; both sacrificed empirical realism for fantasies that were driven by their own goals and hopes resulting in either a greedy or an idealistic projection" (p. 37). His article makes salient how study after study, in diverse fields, have painted an increasingly dark picture of participation. Quandt (2018) discusses, for example, how hateful messages, incivility, manipulation, information wars, misinformation, bullying and trolling have all gained traction in various ways, on the comment fields of proprietary news sites, and/or on a multitude of social media platforms. The article systematically discusses a set of five key dimensions through which the diverse kinds of dark participation can be approached and analyzed: 1.) actors, 2.) reasons, 3.) objects/targets, 4.) audience(s), and 5.) processes.

Ultimately, this thematic issue has attempted to unpack critical issues often overlooked in journalism studies. As Usher and Carlson (2018) put it: "there was much we did not foresee, such as the way that this brave new world would turn journalism into distributed content, not only taking away news organizations' gatekeeping power but also their business model. This is indeed a midlife crisis" (p. 107). Quandt's (2018) article, similarly to those by Lewis and Molyneux (2018) and by Robinson and Wang (2018), offers a systematic and critical review of key issues in much of the research produced over the past decade in the realm of journalism, participation and social media. These articles also set forth important areas that future research can and should look further into.

\section{Closing Words}

In recent decades, many scholars have taken for granted that participatory journalism is positive in nature and that it takes place via the proprietary digital platforms of the news media. This thematic issue presents us with conceptual, critical and empirical articles that should lead us to re-assess our understanding of participation and journalism in an age of social media. This thematic issue has focused on two diverse forms of participation, and the often overlooked importance of who designs, controls and capitalizes on platforms. By accounting for these, this article suggests scholars should rethink what participatory journalism is. In essence, participatory journalism takes place when institutional or individual news producers seek to involve the public in positive forms of participations, whether via proprietary- or nonproprietary platforms, in news production processes or published news materials that strive towards being truthful accounts of world events. Epistemologically speaking, the important matter concerns how journalists and the public interact in processes of news production or in relation to the news material published, and it matters less if such interaction takes place on platforms proprietary or non-proprietary to the news media. 
Altogether, this thematic issue stresses that diverse forms of public interaction taking place on the digital platforms of news media, as well as on non-proprietary social media platforms, are important for the epistemology of participatory journalism. The invited scientific commentaries authored by Katz (2018), Kligler-Vilenchik (2018), Novak (2018), and by Usher and Carlson (2018), each offers important contributions that synthesize the nexus of journalism and participation. Future research should look further into positive and dark participation across diverse platforms. Journalism studies, more specifically, should critically assess the political economy of platform companies in relation to the news media. This relates to how the news media are seeking to enable vis-a-vis disable platform companies in maintaining a dominant role for news distribution and public participation. Many news media have struggled to enable and curate positive forms of participation. After years of giving away news content to social media platforms, as well as enabling the public to engage with the news via non-proprietary platforms, some news organizations have started questioning the long-term consequences of doing so. While Google and Facebook help direct substantial amounts of traffic to news sites, Facebook does less so nowadays. Moreover, this traffic has not led to success on the advertising market, nor do random and non-loyal news users necessarily convert into paying subscribers. Thus, not only should scholars question the nature of participation (which certainly can be dark), or how participation takes place across non-proprietary platforms, but also whether the news media can take for granted that their current strategies for social media platform companies actually bring more positive than negative outcomes. To us, one thing is clear: reader revenues are increasingly becoming more important than advertising revenues for news media organizations, and to succeed with this audience engagement is more important than reach. Consequently, there are news media strategically working with audience engagement on their proprietary platforms, and deemphasizing non-proprietary social media platforms. Importantly, this does not necessarily mean these news media will work towards facilitating active participation with the news.

\section{Acknowledgements}

We are grateful to Scott Eldridge II, Seth C. Lewis and Edson Tandoc Jr. for their invaluable comments on earlier versions and sections of this editorial. The authors thank the Swedish Social Science and Humanities Fund for supporting the work with this thematic issue, and the managing editor of the journal for support throughout the process.

\section{Conflict of Interests}

The authors declare no conflict of interests.

\section{References}

Anderson, C. W., \& Reevers, M. (2018). From counterpower to counter-Pepe: The vagaries of participatory epistemology in a digital age. Media and Communication, 6(4), 24-35.

Baack, S. (2018). Practically engaged. Digital Journalism, 6(6), 673-692. https://doi.org/10.1080/21670811. 2017.1375382

Belair-Gagnon, V. (2015). Social media at BBC news: The re-making of crisis reporting. New York, NY: Routledge.

Boberg, S., Schatto-Eckrodt, M., Frischlich, L., \& Quandt, T. (2018). The moral gatekeeper? Moderation and deletion of user-generated content in a leading news forum. Media and Communication, 6(4), 58-69.

Borger, M., van Hoof, A., Costera Meijer, I., \& Sanders, J. (2013). Constructing participatory journalism as a scholarly object. Digital Journalism, 1(1), 117-134. https://doi.org/10.1080/21670811.2012.740267

Bruns, A. (2012). Reconciling community and commerce? Information, Communication \& Society, 15(6), 815-835. https://doi.org/10.1080/1369118X. 2012.680482

Carlson, M. (2016). Metajournalistic discourse and the meanings of journalism: Definitional control, boundary work, and legitimation. Communication Theory, 26(4), 349-368. https://doi.org/10.1111/ comt.12088

Carlson, M. (2017). Journalistic authority: Legitimating news in the digital era. New York, NY: Columbia University Press.

Carlson, M. (2018). Confronting measurable journalism. Digital Journalism, 6(4), 406-417. https://doi.org/ 10.1080/21670811.2018.1445003

Carlson, M., \& Lewis, S. C. (2015). Boundaries of journalism: Professionalism, practices and participation. London: Routledge.

Cornia, A., Sehl, A., Levy, D. A. L., \& Nielsen, R. K. (2018). Private sector news, social media distribution, and algorithm change (RISJ Report). Oxford: Oxford University Press.

Costera Meijer, I., \& Groot Kormelink, T. (2015). Checking, sharing, clicking and linking: Changing patterns of news use between 2004 and 2014. Digital Journalism, 3(5), 664-679. https://doi.org/10.1080/ 21670811.2014.937149

Deuze, M., \& Witschge, T. (2018). Beyond journalism: Theorizing the transformation of journalism. Journalism: Theory, Practice \& Criticism, 19(2), 165-181. https://doi.org/10.1177/1464884916688550

Ekström, M. (2002). Epistemologies of TV journalism. Journalism: Theory, Practice \& Criticism, 3(3), 259282. https://doi.org/10.1177/146488490200300301

Ekström, M., \& Westlund, O. (in press). Journalism and epistemology. In Oxford encyclopedia of journalism studies. Oxford: Oxford University Press.

Eldridge, S. A. (2018). Online journalism from the periph- 
ery: Interloper media and the journalistic field. London: Routledge.

Ferrer, R. C., \& Karlsson, M. (2018). Native advertising and the appropriation of journalistic clout. In B. Franklin \& S. Eldridge II (Eds.), The Routledge handbook of developments in digital journalism studies (pp. 463-474). London: Routledge.

Hermida, A., Lewis, S. C., \& Zamith, R. (2014). Sourcing the Arab Spring: A case study of Andy Carvin's sources on Twitter during the Tunisian and Egyptian revolutions. Journal of Computer-Mediated Communication, 19(3), 479-499. https://doi.org/10.1111/ jcc4.12074

Holt, K. (2018). Alternative media and the notion of antisystemness: Towards an analytical framework. Media and Communication, 6(4), 49-57.

Holton, A., \& Belair-Gagnon, V. (2018). Strangers to the game? Interlopers, intralopers, and shifting news production. Media and Communication, 6(4), 70-78.

Holton, A., \& Molyneux, L. (2018). Social media and journalistic branding. Explication, enactment, and impact. In B. Franklin \& S. Eldridge II (Eds.), The Routledge handbook of developments in digital journalism studies (pp. 441-449). London: Routledge.

Karlsson, M., Bergström, A., Clerwall, C., \& Fast, K. (2015). Participatory journalism-The (r)evolution that wasn't. Content and user behavior in Sweden 2007-2013. Journal of Computer-Mediated Communication, 20(3), 295-311. https://doi.org/10.1111/ jcc4.12115

Katz, J. E. (2018). Commentary on news and participation through and beyond proprietary platforms in an age of social media. Media and Communication, 6(4), 103-106.

Kligler-Vilenchik, N. (2018). Why we should keep studying good (and everyday) participation: An analogy to political participation. Media and Communication, 6(4), 111-114.

Kligler-Vilenchik, N., \& Tenenboim, O. (in press). Sustained journalist-audience reciprocity in a mesonewspace: The case of a journalistic WhatsApp group. New Media \& Society.

Lewis, S. C. (2012). The tension between professional control and open participation. Information, Communication \& Society, 15(6), 836-866. https:// doi.org/10.1080/1369118X.2012.674150

Lewis, S. C., Holton, A. E., \& Coddington, M. (2014). Reciprocal journalism. Journalism Practice, 8(2), 229-241. https://doi.org/10.1080/17512786.2013.859840

Lewis, S. C., \& Molyneux, L. (2018). A decade of research on social media and journalism: Assumptions, blind spots, and a way forward. Media and Communication, 6(4), 11-23.

Lewis, S. C., \& Westlund, O. (2015). Actors, actants, audiences, and activities in cross-media news work. Digital Journalism, 3(1), 19-37. https://doi.org/10.1080/ 21670811.2014.927986

Ling, R. S. (2012). Taken for grantedness: The embedding of mobile communication into society. Cambridge,
MA: MIT Press.

Nielsen, R. K. (2012). How newspapers began to blog: Recognizing the role of technologists in old media organizations' development of new media technologies. Information, Communication \& Society, 15(6), 959-978. https://doi.org/10.1080/1369118X. 2012.694898

Nielsen, R. K. (2016). The business of news. In T. Witschge, C. W. Anderson, D. Domingo, \& A. Hermida (Eds.), The SAGE handbook of digital journalism (pp. 128-143). London: SAGE Publications.

Novak, A. (2018). Designing a renaissance for digital news media. Media and Communication, 6(4), 115-118.

Peters, C., \& Broersma, M. (2016). Rethinking journalism again: Societal role and public relevance in a digital age. London: Routledge.

Powers, E. (2018). Selecting metrics, reflecting norms. Digital Journalism, 6(4), 454-471. https://doi.org/ 10.1080/21670811.2018.1445002

Quandt, T. (2018). Dark participation. Media and Communication, 6(4), 36-48.

Robinson, S., \& Wang, Y. (2018). Networked news participation: Future pathways. Media and Communication, 6(4), 91-102.

Ruotsalainen, J., \& Villi, M. (2018). Hybrid engagement: Discourses and scenarios of entrepreneurial journalism. Media and Communication, 6(4), 79-90.

Singer, J. B., Domingo, D., Heinonen, A., Hermida, A., Paulussen, S., Quandt, T., ... Vujnovic, M. (2011). Participatory journalism: Guarding open gates at online newspapers. Malden, MA: Wiley-Blackwell.

Swart, J., Broersma, M., \& Peters, C. (2018). Sharing and discussing news in private social media groups. Digital Journalism. https://doi.org/10.1080/ 21670811.2018.1465351

Swart, J., Peters, C., \& Broersma, M. (2018). Shedding light on the dark social: The connective role of news and journalism in social media communities. New Media \& Society. https://doi.org/10.1177/ 1461444818772063

Thorsen, E., \& Jackson, D. (2018). Seven characteristics defining online news formats. Towards a typology of online news and live blogs. Digital Journalism, 6(7), 847-868.

Usher, N., \& Carlson, M. (2018). The midlife crisis of the network society. Media and Communication, 6(4), 107-110.

Van Leuven, S., Kruikemeier, S.,Lecheler, S., \& Hermans, L. (2018). Online and newsworthy. Have online sources changed journalism? Digital Journalism, 6(7), 798-806.

Westlund, O. (2011). Cross-media news work sensemaking of the mobile media (r)evolution (Unpublished Doctoral dissertation). University of Gothenburg, Gothenburg, Sweden.

Witschge, T., \& Harbers, F. (2018). The entrepreneurial journalist. In. B, Franklin \& S. Eldridge II (Eds.), The Routledge handbook of developments in digital journalism studies (pp. 64-76). London: Routledge. 


\section{COGITATIO}

\section{About the Authors}

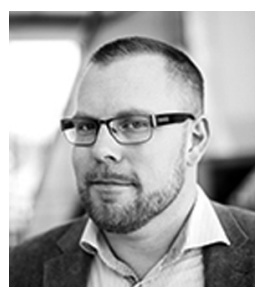

Oscar Westlund (PhD) is Professor at the Department of Journalism and Media Studies at Oslo Metropolitan University, where he leads the OsloMet Digital Journalism Research Group. He holds secondary appointments at Volda University College and University of Gothenburg. Westlund specializes in journalism, media management and news media consumption for proprietary news media platforms such as news sites and mobile applications, as well as with regards to social media platforms. Westlund is the Editor-in-Chief of Digital Journalism, and has also guest edited special issues for a handful other leading international journals. He currently leads a research project called the epistemologies of digital news production, funded by the Swedish Foundation for Humanities and Social Sciences.

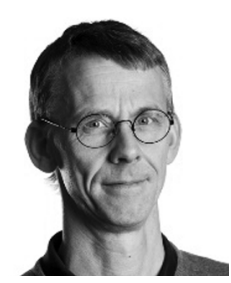

Mats Ekström (PhD) is Professor at the Department of Journalism, Media and Communication at the University of Gothenburg. His research focuses on journalism, media discourse, conversation in institutional settings, political communication and young people's political engagement. Recent publications include "Right-wing populism and the dynamics of style" (Palgrave Communications, 2018, with Marianna Patrona and Joanna Thornborrow); "Social media, porous boundaries, and the development of online political engagement among young citizens" (New Media \& Society, 2018, with Adam Shehata) and The Mediated Politics of Europe: A Comparative Study of Discourse (Palgrave, 2017, with Julie Firmstone). 